\title{
EXPLOITING 3D MULTISPECTRAL TEXTURE FOR A BETTER FEATURE IDENTIFICATION FOR CULTURAL HERITAGE
}

\author{
A. Mathys ${ }^{1,2,3,{ }^{*}, \text { R. Jadinon }}{ }^{1}$, P. Hallot ${ }^{3}$ \\ ${ }^{1}$ Royal Museum for Central Africa, Leuvensesteenweg 13, 3080 Tervuren, Belgium (aurore.mathys, \\ remy.jadinon)@africamuseum.be \\ ${ }^{2}$ Royal Belgian Institute of Natural Sciences, Rue Vautier 29, 1000 Brussels, Belgium \\ ${ }^{3}$ University of Liège, Bd de la Constitution 41, 4020 Liège, Belgium p.hallot@uliege.be
}

Commission II, WG II/8

KEY WORDS: Cultural Heritage documentation, Spectral imaging, Infrared, Ultraviolet, Mpungi, Perforated baton, Dense image matching, 3D reconstruction

\begin{abstract}
:
3D photogrammetric reconstruction and spectral imaging have already proven useful and are being used on a daily basis for studying cultural heritage. Dense Image Matching allows to create a virtual replica of the object that can be used for morphometric studies, for monitoring and conservation purposes, virtual access, reduced handling of fragile objects and share objects with a broad audience. 2D spectral imaging is used in the field of cultural heritage conservation to analyse the condition of an object, map a previous restoration, detect a change in composition, reveal sub-drawings, improve details, etc. A 2D image representation of a three-dimensional object is a limited field of view and lead frequently to a lack of information, especially for artifacts with complex geometries. The combination of both techniques is the next step toward a more complete and more objective record of an object, but it can also be a tool to improve the identification of details presents on artifacts. This study focuses on a methodology aiming to combine photogrammetry and spectral imagery acquired from a modified DSLR camera. Two case studies acquired with multispectral reconstruction techniques are analysed. They are used to demonstrate the advantages and disadvantages of the developed methodology. The obtained results show that spectral imaging reconstruction is highly related to used wavelengths. Infrared and ultraviolet fluorescence can enhance features identification of the objects that are not or less visible in classic white light photogrammetry. Combining 3D reconstruction and multispectral imagery can facilitate the readings and the understanding of the object. It can help conservator and researchers to better understand the objects and how to preserve them.
\end{abstract}

\section{INTRODUCTION}

Photogrammetry is today the most versatile technology in order to produce high-resolution $3 \mathrm{D}$ models with accurate colours. It can be applied to small specimens or on very large objects with a similar general strategy. It is easily portable on the field and cheaper to many $3 \mathrm{D}$ acquisition scanners. This technology is now daily used by many museums and research institution in order to digitize cultural heritage collections.

3D digitization is useful in many fields for cultural heritage and conservation: many organic materials are bound to disappear over time despite our best conservation efforts. 3D digitization allows having a virtual back-up of the object (Remondino \& Stylianidis, 2016). It reduces the need for manipulation of fragile objects as they can be virtually manipulated. It allows to share objects with scientist across the world without the need of moving an object, it is especially useful to allow studies of artifacts found on modern excavations that cannot cross borders due to modern legislation. Replicas can be 3D printed to allow the public and especially disabled people to manipulate objects (Ballarin et al., 2018; Neumüller et al., 2014). Virtual 3D models also help restoration field to virtually restore an object or formulate a hypothesis of how the object looked (Acke et al., 2018; Arbace et al., 2013; Hawotte, 2014; Zhao et al., 2018). It can be used in science for morphometrics (Chacón et al., 2016; Selden et al., 2014) or a comparison of similar objects in different museums or countries.
Human vision is limited to the visible spectrum (between 400 and $700 \mathrm{~nm}$ ) but cameras can allow us to capture information in the ultraviolet (UV) and infrared (IR) spectrum. This can add a valuable layer of information to the object.

Spectral imaging is used in the cultural heritage and conservation field since the early 1990s (Liang, 2012) and is now commonly used. Its application cover a large field of application: visualization of underdrawings or pentimenti in paintings characterization of pigments and inks in painted artefacts (McCouat, 2014; Accorsi et al. 2009) and drawings, study of palimpsest (Hansen, 2006; Easton \& Noël, 2004), imaging of ancient manuscript/documents (Hollaus et al. 2012; Marengo et al. 2011), differentiation of organic binding media, monitoring and evaluate conservation treatments for painting (Fischer \& Kakoulli 2006). Spectral imaging has also been successfully used for 3D objects like ostraca's (Faigenbaum, 2012), Egyptian execration statuettes (Boschloos, 2016; Delvaux et al. 2017), vases and statues (Webb, 2017) or even rock art (Fredlund \& Sundstrom, 2015).

Imaging 3D objects with 2D images has its limitations and don't provide as complete information as a multispectral 3D would. In recent years more and more initiatives have been launched to combine multispectral and 3D (Delvaux, 2017; Delcourt, 2010; Lerma, 2011; Simon et al. 2013, Buccarella Hedeaard et al., 2019). In the following study, spectral imaging is combined with photogrammetry and we evaluate the gain of the combination.

\footnotetext{
* Corresponding author
} 


\section{METHODOLOGY AND DATA ACQUISITION PROCESS}

In order to combine 3D reconstruction and multispectral imaging, the photogrammetry method was chosen as it is easy to adapt to multispectral, it is low cost, portable and versatile in size/resolution.

Multispectral imaging consists in acquiring images over several specific bands of light spectrum. For the purpose of this study, we only focus on ultraviolet of type A (UV-A), visible (VIS) spectrum and near-infrared (NIR). UV-A is the least annoying part of UV, we do not wish to apply UV-B or UV-C because exposure to these parts of UV can be responsible for degrading organic material.

Designation of spectral ranges varies often with the application (Fischer \& Kakoulli). In the next, we will refer to the following nomenclature: UV-A 315-400 nm, VIS 400-700 nm, NIR 700$1100 \mathrm{~nm}$ (Verhoeven, 2017).

For the multispectral photogrammetry, we chose a modified DSLR camera (Canon 5Ds). The advantage of using such type of camera over a dedicated multispectral camera is the resolution and the cost. Most multispectral dedicated cameras have low resolution. Moreover, many have a restricted spectrum that doesn't allow to capture near UV and near IR with the same camera. The Canon 5Ds has a CMOS which is a silicon sensor. The theoretical photosensitivity of the CMOS sensor is governed by the silicon spectral response (Jain, 2016) and should be between 200 and $1100 \mathrm{~nm}$ (Gilblom \& Yoo, 2004; Richards, 2005). In practice, this is variable depending on the model of the CMOS sensor and therefore on the camera. More recently the sensitivity of CMOS sensor can be extended by hybrid integration of materials with a longer wavelength photoresponsitivity (Ohta, 2017; Richards, 2005), therefore it is possible that some cameras have a more extended sensitivity.

The classical DSLRs are equipped with an IR cut-off filter in front of the sensor. In a modified DSLR, this IR filter is removed and replaced by a Schott N-WG280 clear filter ${ }^{1}$ that allows passing wavelengths from approximately $280 \mathrm{~nm}$ to $2750 \mathrm{~nm}$, enabling to keep the optical properties of the camera and capture the full spectrum.

The camera body was mounted with a high-performance lens, the CoastalOpt $60 \mathrm{~mm}$ from Jenoptik Optical system ${ }^{2}$. The CoastalOpt $60 \mathrm{~mm}$ is a multispectral dedicated lens covering the spectrum from 290 to $1500 \mathrm{~nm}$ and colour corrected from 310 to $1100 \mathrm{~nm}$. This means refocusing isn't required when switching wavelengths. It is known to be very finely resolved (sharp). It is a lens made of a combination of quartz and fluorite instead of a glass lens, enabling to pass more reflected UV than the normal glass lenses. Therefore, our spectrum of interest is reduced to 315 to $1100 \mathrm{~nm}$

For illumination, we illuminate the scene with LED lights panels with specific wavelengths $(365 \mathrm{~nm}, 385 \mathrm{~nm}, 395 \mathrm{~nm}, 420 \mathrm{~nm}$, $450 \mathrm{~nm}, 470 \mathrm{~nm}, 505 \mathrm{~nm}, 530 \mathrm{~nm}, 560 \mathrm{~nm}, 590 \mathrm{~nm}, 615 \mathrm{~nm}, 630 \mathrm{~nm}$, $655 \mathrm{~nm}, 735 \mathrm{~nm}, 850 \mathrm{~nm}, 950 \mathrm{~nm}$, and white light). LEDs were chosen because (i) LED lights generates less heat (variation of temperature can damage a fragile object or have an impact on the

${ }^{1} \mathrm{https} / / /$ www.schott.com/advanced_optics/english/products/opti cal-components/optical-filters/optical-filter-glass/index.html $(29 / 06 / 2019)$
3D reconstruction); (ii) it limits the number of filters used, therefore the manipulations (i.e. gain of time of capture). LED lights with wavelengths below $365 \mathrm{~nm}$ and above $950 \mathrm{~nm}$ are hard to find and very expensive therefore they weren't considered for this first study since the developed infrastructure aims at being low cost.

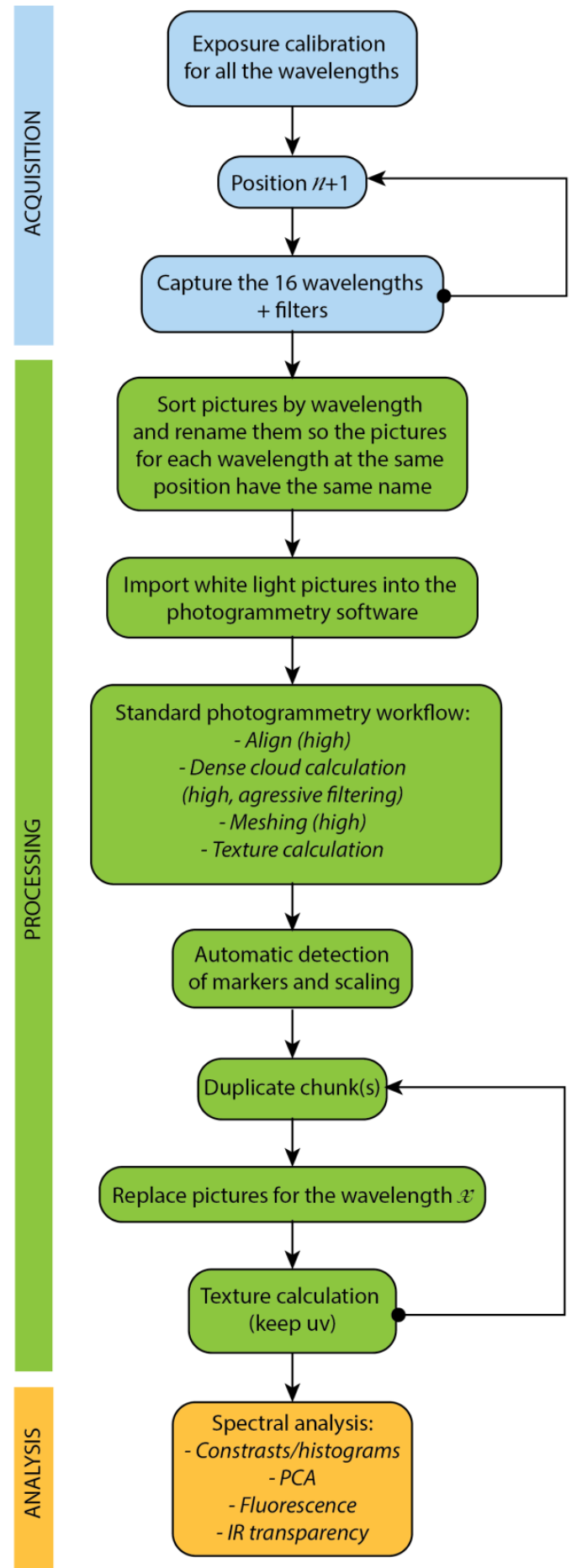

Figure 1: Theoretical workflow of data acquisition, processing and analysis

2 https://www.jenoptik.com/products/opticalsystems/customized-and-standardized-objectivelenses/multispectral-objective-lenses (21/02/2019) 
Images of the objects are captured at the same position for each wavelength. They include photogrammetry markers and colour charts for scaling and colour calibration. Exposure time is set for each wavelength using a colour chart and a spectrophotometer white target prior to the capture. Data is captured in Canon RAW format. The images are directly imported into Agisoft Photoscan Pro 1.4.2 (AgiSoft, 2018; now known as Metashape) in order to calculate the 3D model using self-calibration (alignment, dense point cloud calculation with aggressive filtering, textured mesh generation). The models are scaled using coded photogrammetry markers, automatically detected by the photogrammetry software (Figure 1).

Evaluation of the quality of the 3D models won't be addressed in this paper as several studies have already assessed that white light photogrammetry is a reliable reconstruction technique (Giacomini et al., 2019; Maté-González et al., 2017). In this paper we focus on the textural information gained by spectral photogrammetry, but not on the metric quality/differences of the 3D obtained at the different wavelengths. Analysis of the texture is performed in ImageJ. They consist in contrast analysis, features extraction, fluorescence and transparency to certain wavelengths and principal component analysis (PCA).

\section{CASES STUDIES}

\subsection{Ivory horn mpungi (RMCA)}

The mpungi ivory horn MO.1967.63.802 has been collected in 1983 by Edmond Dartevelle during a field expedition of the Royal Museum of Congo, near the coast of Angola. Archives of the Royal Museum for Central Africa (RMCA) indicates the object to be from the Solongo population ${ }^{3}$. Solongo people are part of the Kongo linguistic sub-group from the Zaïre province in Northwest of Angola, near the border of Congo Democratic Republic.

Mpungi is a generic term designating horns in Kikongo language. In Kongo musical traditions, mpungi horns are symbols of the power of traditional authority. They integrate the emblematic orchestral group of Kongo culture: masikulu ensemble. A masikulu ensemble is composed of five mpungi horns and two drums. They occur when a high dignitary decease, during the burial, the mourning ceremonial, but also for the enthronement of the new chief (Kabolo Iko, 2004) or for the execution of a condemned. Literature from the beginning of the 20th century indicates that these objects were highly considered by the local population, that they were linked to the ancestor cult and that the fate of those who wanted to acquire them was unenviable (Söderbergh, 1956). Unfortunately, the archives of RMCA don't give information on how it was acquired.

The mpungi shape naturally reminds one of the elephant tusk from which it has been carved. Sometimes the instrument could be elongated by a wooden pavilion.

The mpungi MO.1967.63.802 is carved of decorative motif all along its body, with a geometric pattern of Kongo style but also a cross suggesting European or Christian influence (Cooksey et al., 2013). This hypothesis is supported by the rounded strap fastener on the convex part of the instrument and by the terminal knob, both unusual for the ivory horn of the region. The horn has been coloured with a dark reddish-brown coating, probably wood smoke, and palm oil, making it difficult to read the patterns.

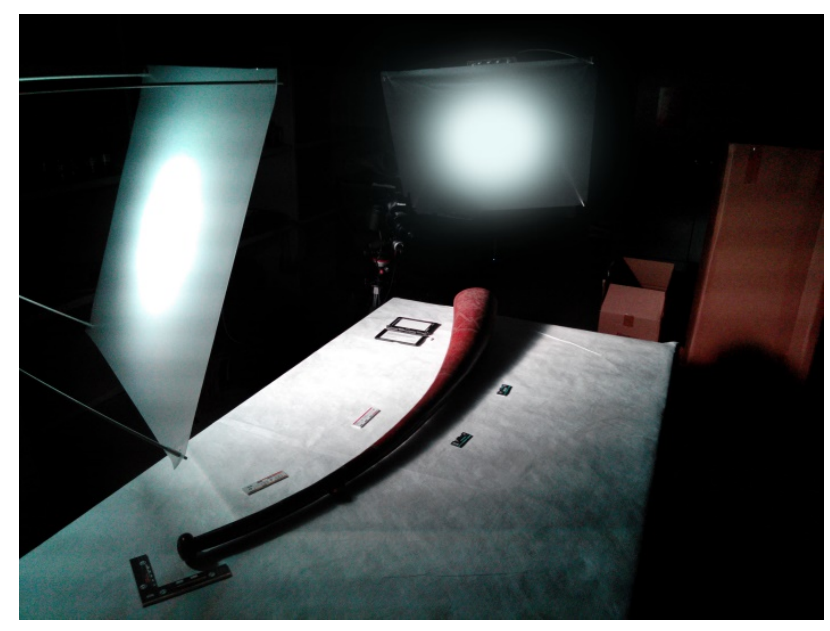

Figure 2: Multispectral photogrammetry setup used to digitize the horn.

We digitalized the horn with the multispectral process presented in figure 1 with 112 positions (Figure 2). The picture for each wavelength is captured at the exact same position for all the wavelengths. This is of high importance since the $3 \mathrm{D}$ geometric reconstruction is performed on one class of wavelength. Misalignment will cause an error in the reconstruction and the texture application of others wavelength. The model is calculated using the white light pictures in the photogrammetry software, but pictures of the darker part of the horn (e.g. the narrower side) didn't align. The darker part is also the most reflective part.

The analysis of the spectral images showed that the dark patina is invisible to IR. In IR the ivory is shown as light coloured and the details of the ivory are very clear. Therefore, a second chunk was created with only pictures of the narrower tip in IR. This enabled a correct $3 \mathrm{D}$ reconstruction of the narrow tip. Next, the two chunks were aligned together and merged in order to reconstruct the complete horn. The pictures in IR were replaced by the same one in white light before calculating the complete model (Figure 3).

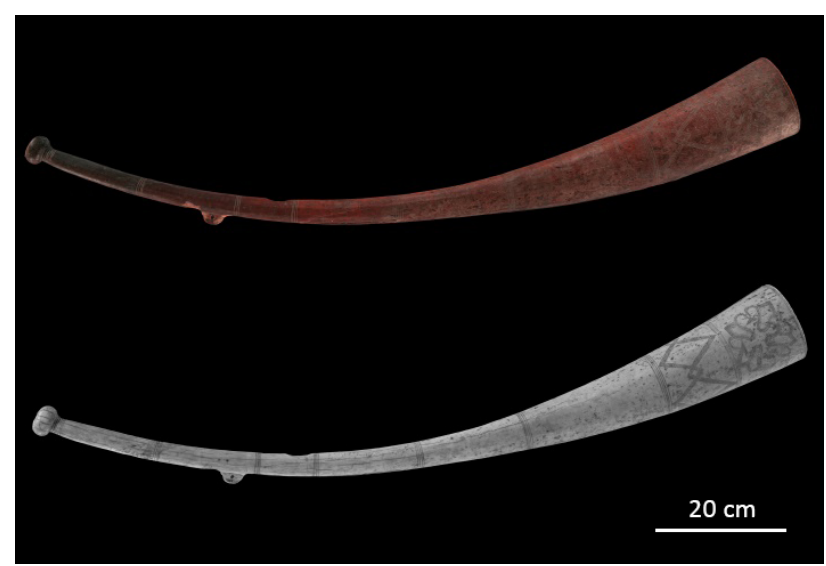

Figure 3: General view of the 3D model of the horn in visible light on top (https://sketchfab.com/3d-models/mo1967638023 e9f6aae6bde4c269bf36795f15ab1d5) and in infrared on the bottom (https://sketchfab.com/3d-models/mo196763802950nm-ce3d430f695b4e43af9e991d59676956). The engravings are more clearly visible on the IR model.

\footnotetext{
${ }^{3}$ Also known as Sorongo
} 

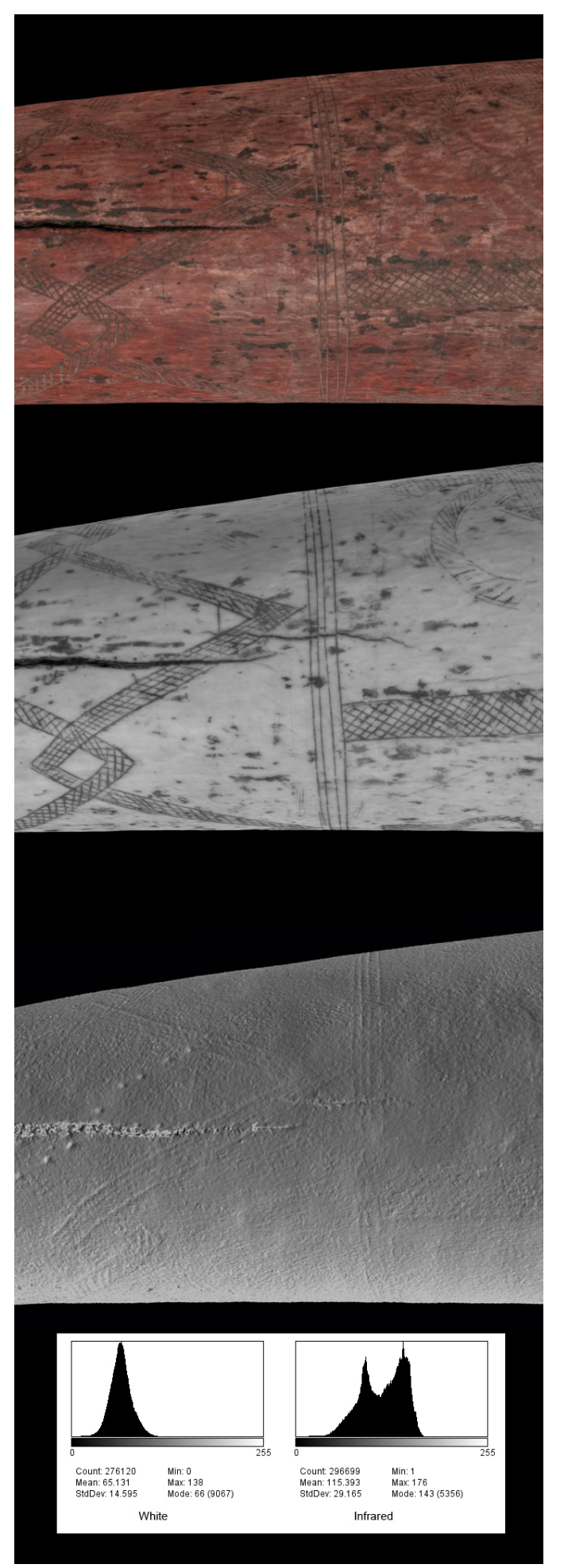

Figure 4: Detail of the horn with white light and IR texture and without texture. The IR model enhance the presence of some cracks that are less visible in white light and allow a better reading of the pattern than the mesh. Histogram of the white light and IR texture are situated at the bottom of the image showing a broader repartition of pixels for IR.

The model was textured with white light pictures and with all the 16 wavelengths by replacing the pictures as they were captured from the same position. Each of the 16 textured models were reviewed in order to determine the added value of the texture of each wavelength (contrasted features, features visible or absent from one wavelength to another, fluorescing features, etc.). Result of this analysis showed the most informative textures for the horn were white light and IR. The histogram of the IR texture shows a broader repartition than in white light, with a profile characteristic of higher contrast (Figure 4).

White light texture is always important as it represents our way of perceiving the object, it is realistic.

The IR texture, in this case, has allowed enhancing the engravings which allow to see them clearly while it wasn't the case in visible light (Figures 3 and 4). They also enhance cracks, scratches and faded drawings. The engraved pattern is only partially recorded by the $3 \mathrm{D}$ model, therefore the infrared texture is of particular interest as it corresponds to the more complete and more contrasted recording of the pattern (Figure 4). Applying PCA to the sequence of spectral textures allowed to obtain an image showing contrasted features from both visible wavelengths and infrared (Figure 5).

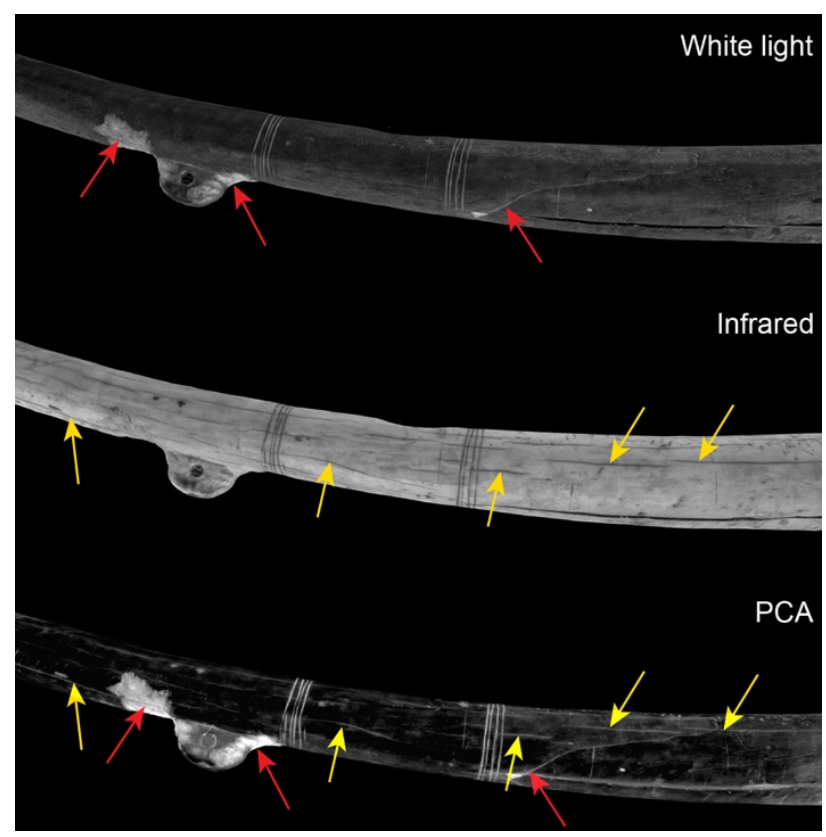

Figure 5: PCA of the spectral data allows to combine features (indicated by the arrows) from both visible and infrared texture.

\subsection{Engraved antler from Trou des Nutons (RBINS)}

The artifact from "Trou des Nutons" is a fragment of a decorated antler dated from the Magdalenian period (Upper Palaeolithic) of Belgium. It has been found on the site of Trou des Nutons (Furfooz, Belgium) by E. Dupont on the excavation of 1864 (Lejeune, 1987) and is part of the prehistoric collection of the Royal Belgian Institute of Natural Sciences (RBINS). The fragment is $138 \mathrm{~mm}$ long and is probably a fragment of a perforated baton.

Perforated baton, also known as "bâton percé" or "bâton de commandement", are artifacts created from an antler. As the name indicates they have at least one perforation (Peltier, 1992) and an elongated part. In this case, only the elongated part was found. Many hypotheses on the function of perforated batons have been proposed and the real function is still unknown (Rigaud, 2001; Lompre, 2003). Perforated batons are found in 
European sites during superior Palaeolithic from Aurignacian to Magdalenian (Rigaud, 2001; Kipfer, 2008). The engravings iconography is quite simple during Aurignacian and becomes more elaborated and naturalistic during Magdalenian with the representation of animals.

This fragment is decorated on both sides with on one side what seems to be a schematic first outline silhouette of what could be an aurochs. The other side is engraved of a more complex figure recognize as a bison (Twiesselmann, 1975) similar to the one of the perforated baton from Isturitz (Pyrénées-Atlantiques, France) and typical for Magdalenian (Lejeune, 1987). But if you turn this same figure upside-down, some will see the representation of a mammoth (Figure 6). The 3D model will allow the viewer to forge its own opinion.

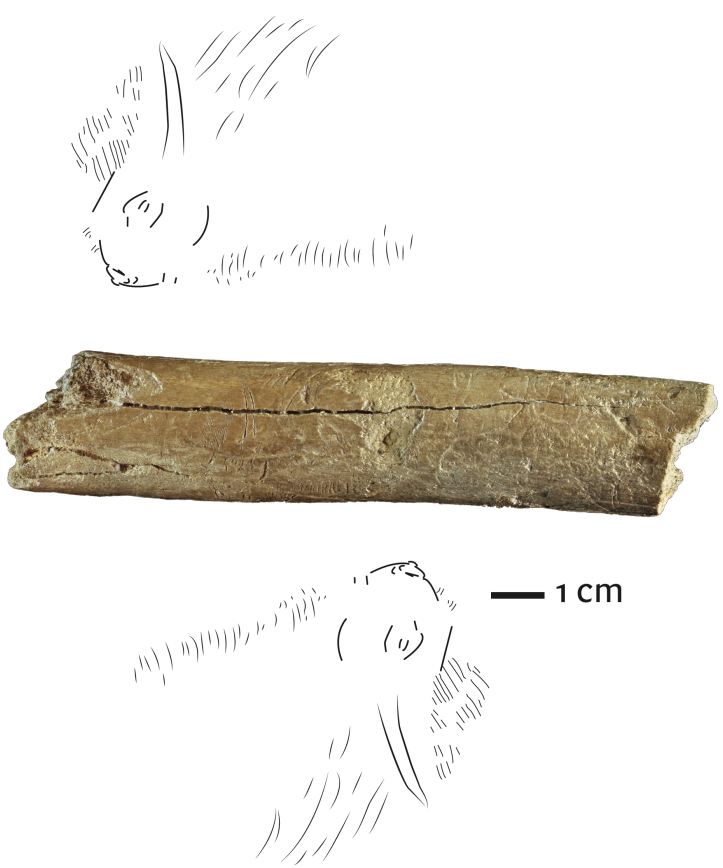

Figure 6: Turning the engraving upside down to interpret the pattern differently.

The multispectral photogrammetry model was obtained from 20 views in each wavelength for only one side, using the workflow presented in figure 1 .

As we can see on figure 7 , the distribution of the intensity histograms between the two models shows clearly a broader repartition of pixels in the ultraviolet fluorescence (UVF) case (std 1 vs std 2). This indicates that UVF texture is more contrasted, which leads to better visibility of features elements presented on the model. It is the case of the engravings and the degradation state of the artifact (Figure 7).

Again, the advantage of having a 3D model is that the object can be rotated to see engravings on both sides and it can be rotated to see the engraving both from the top and inverted. In addition, the texture can be removed to see the engraving without any influence of the texture, but also, if the quality of the models allows it, study bone surface modifications (Maté-González et al., 2015; Maté-González et al., 2017), monitor dimensional stability and surface degradation (Hess et al., 2015), measure curvatures (De Groote et al., 2010), etc.

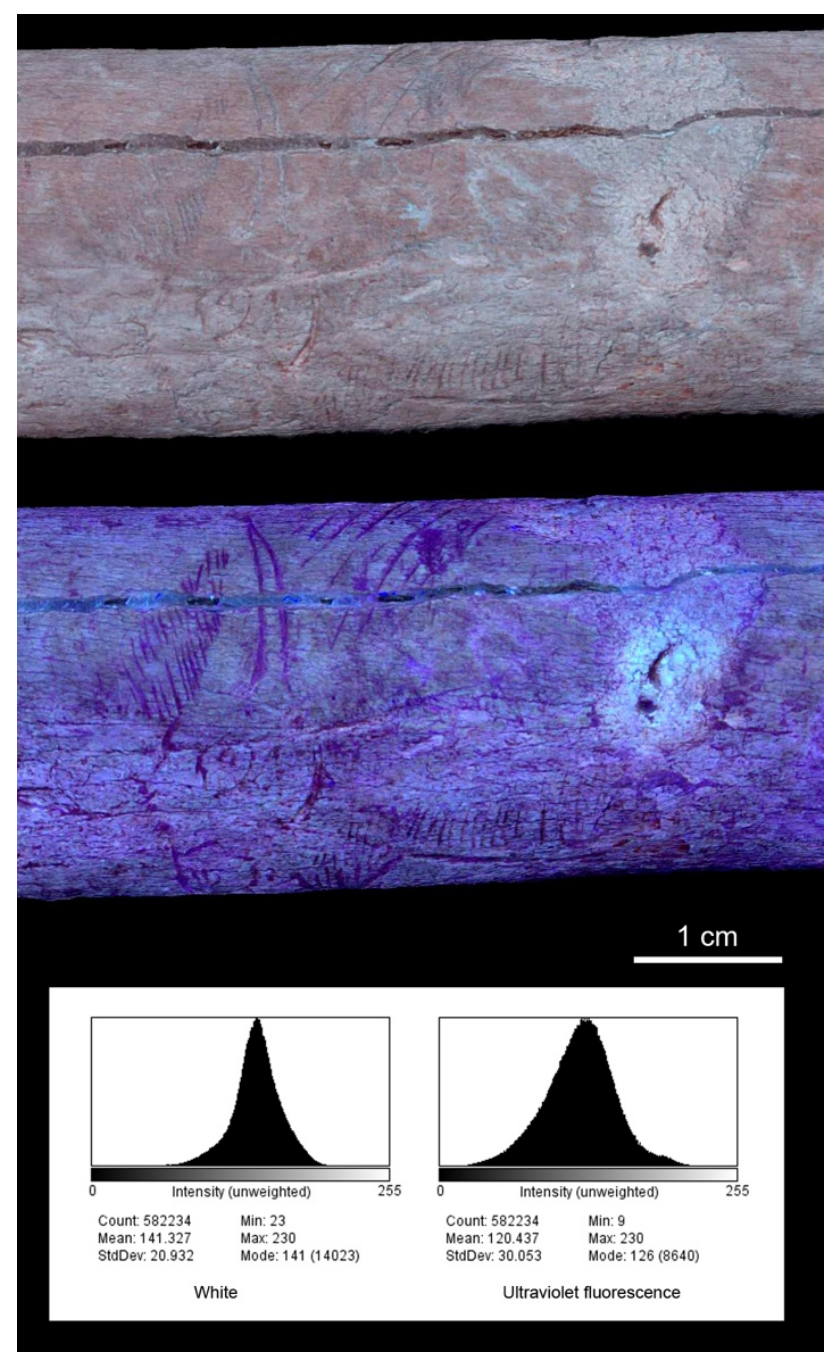

Figure 7: Detail of the 3D model with visible texture on top (https://sketchfab.com/3d-

models/1490299c639643ee834fe3a0cd8578ee) and ultraviolet fluorescence texture on bottom (https://sketchfab.com/3dmodels/2eef8001f89f4802ab8866806a7e7fb5). The engravings and small cracks are displayed as darker elements in UVF, while the part where the damage goes deeper is display in a light shade of blue in UVF.

\section{DISCUSSION AND PERSPECTIVES}

The case studies presented here are captured by multispectral photogrammetry. For both the horn and the engraved antler, the use of multispectral imaging allowed to increase contrast, but for the first, it is IR that increased the visibility of the engravings and for the latter, it is UVF that improved the visibility of the engraving. The use of alternative texture et specific wavelengths is an easy method to improve the legibility of the engravings without the use of complex equipment or time-consuming techniques. In addition, the use of advanced image processing techniques like PCA enables to further enhance contrast and combine features from different wavelengths. Further analysis could be made using spectral classification techniques.

The use of multispectral 3D facilitates the recording of the engravings as all the objects studied were three-dimensional and a 2D picture wouldn't have recorded the decoration as accurately. 
Both objects are fragile and both are already cracked on most of their length; therefore having a 3D model can be a virtual backup and can be used to monitor in the future the evolution of the object's state.

To summarize, the results showed different things: (i) the use of different wavelength can enable to increase contrasts; (ii) allying $3 \mathrm{D}$ and multispectral is helpful to understand and read the object; (iii) multispectral imaging can help calculating photogrammetry models for challenging materials.

Future research will analyse classification methods and accuracy or differences of models obtained at specific wavelengths.

\section{ACKNOWLEDGMENTS}

Authors wish to acknowledge Jonathan Brecko, Patrick Semal and Didier Van den Spiegel for the support and brainstorming.

Authors wish to acknowledge Stéphane, Marieke, Anoek, Siska from the conservation team at RMCA for the manipulation and the space to digitize the horn. Also Els Cornelissen for the access to the ethnographical collection of RMCA.

\section{REFERENCES}

Accorsi, G., Verri, G., Bolognesi, M., Armaroli, N., Clementi, C., Miliani C. and Romani, A., 2009. The exceptional near-infrared luminescence of cuprorivaite (Egyptian blue). Chemical Communications, 23, pp. 3392-3394.

https://doi.org/10.1039/B902563D

Acke, L., De Vis, K., De Kock, T., Indekeu, E., Van Goethem, J., Van Akeleyen, J., Cornelis, M., Verlinden, J., Verwulgen, S., 2018. Treatise of Digital Reconstruction and Restauration of Lace Porcelain. In: Ioannides, M., et al. (eds) Digital Heritage. Progress in Cultural Heritage: Documentation, Preservation, and Protection. EuroMed 2018. Lecture Notes in Computer Science, vol 11196, pp. 15-26.

AgiSoft, 2018. Agisoft PhotoScan Professional Software, Version 1.4.3. http://www.agisoft.com/downloads/installer/ (August 2018)

Arbace, L., Sonnino, E., Callieri, M., Dellepiane, M., Fabbri, M., Idelson, A.I., Scopigno, R., 2013. Innovative uses of 3D digital technologies to assist the restoration of a fragmented terracotta statue. Journal of Cultural Heritage 14, pp. 332-345.

Ballarin, M., Balletti, C., and Vernier, P., 2018. Replicas in cultural heritage: 3D printing and the museum experience. Int. Arch. Photogramm. Remote Sens. Spatial Inf. Sci., XLII-2, 5562. https://doi.org/10.5194/isprs-archives-XLII-2-55-2018

Boschloos, V., Hameeuw, H., and Van der Perre, A., 2016. New Lights on the Brussels Egyptian Execration Figurines. Poster at the ASOR meeting, (San Antonio, 16-19 November 2016).

Buccarella Hedeaard, S., Brøns, C., Drug, I., Saulins, P., Bercu, C., Jakovlev, A., and Kjaer, L., 2019. Multispectral Photogrammetry: 3D models highlighting traces of paint on ancient sculptures. In: Proceedings of the Digital Humanities in the Nordic Countries (DHN) 4th Conference, Copenhagen, March 6-8 2019, pp 181-189.

Chacón, M.G., Détroit, F., Coudenneau, A., and Moncel, M- H., 2016. Morphometric assessment of convergent tool technology and Function during the Early Middle Palaeolithic: The case of Payre, France. PLoS one, 11(5).

Cooksey, S., Poynor, R., and Van Hee, H., 2013. Kongo across the Waters. Collaborative exhibition and publication. Gainesville - Tervuren: Harn Museum \& RMCA. pp. 62.

Darmont, A., 2009. Spectral Response of Silicon Image Sensors. Aphesa, White paper.

https://britastro.org/sites/default/files/attachments/SpectralResp onse WhitePaper_April09.pdf (21/02/2019)

De Groote, I., Lockwood, C.A., and Aiello, L.C., 2010. Technical note: A new method for measuring long bone curvature using 3D landmarks and semi-landmarks. American Journal of Physical Anthropology, 141, pp. 658-664. https://doi.org/10.1002/ajpa.21225

Delcourt, J., 2010. Un système intégré d'acquisition 3D multispectral : acquisition, codage et compression des données. Informatique [cs], Université de Bourgogne, France.

Delvaux, L., Hameeuw, H., Van der Perre, A., Boschloos, V., Ossieur, F., Vandermeulen, B., Proesmans, M., Braekmans, D., 2017. Conservation, IR, UV and 3D-Imaging: The Egyptian Execration Statuettes Project. Final Report, Belgian Science Policy - Brussels, Belgium.

https://doi.org/10.13140/RG.2.2.10989.28649

Easton, R.L., and Noël, W., 2004. The multispectral imaging of the Archimedes Palimpsest. Gazette du livre médiéval 45, pp. 39-49.

Faigenbaum, S., Sober, B., Shaus, A., Moinester, M., Piasetzky, E., Bearman, G., Cordonsky, M., and Finkelstein, I., 2012. Multispectral images of ostraca: acquisition and analysis. Journal of Archaeological Sciences 39, pp. 3581-3590.

Giacomini, G., Scaravelli, D., Herrel, A., Veneziano, A., Russo, D., Brown, R.P., and Meloro, C., 2019. 3D photogrammetry of Bat Skulls: Perspectives for Macro-evolutionary Analyses. Evolutionary Biology. https://doi.org/10.1007/s11692-01909478-6

Gilblom, D.L., and Yoo, S.K., 2004. Infrared and ultraviolet imaging with a CMOS having layered photodiodes In: Proc. SPIE 5301, Sensors and Camera Systems for Scientific, Industrial, and Digital Photography Applications V, (7 June 2004). https://doi.org/10.1117/12.528427

Hansen, D.M., 2006. Multispectral imaging and analysis of the Archimedes Palimpsest. Thesis, Rochester Institute of Technology, USA.

Hawotte, S., 2014. L'impression 3D au service du traitement de conservation restauration d'une tulipière en faïence de Delft. Bulletin 04, pp. 15-19.

Hess, M., Korenberg, C., Ward, C., Robson, S., and Entwistle, C., 2015. Use of 3D laser scanning for monitoring the dimensional stability of a Byzantine ivory panel, Studies in Conservation, 60:sup1, pp. https://doi.org/10.1179/0039363015Z.000000000217

Hollaus, F., Gau, M., and Sablatnig, R., 2012. Multispectral Image Acquisition of Ancient Manuscripts In: Progress in 
Cultural Heritage Preservation. EuroMed 2012. Lecture Notes in Computer Science, vol 7616, pp. 30-39. Springer, Berlin, Heidelberg. https://doi.org/10.1007/978-3-642-34234-9_4

Jain, U., 2016. Characterization of CMOS Image Sensor. Master Thesis from Delft, University of Technology, Netherlands.

Kabolo Iko, K., 2004. Le royaume kongo et la mission catholique, 1750-1838: du déclin à l'extinction. Paris : Karthala.

Kipfer, B.A., 2008. Dictionary of Artifacts. John Wiley \& sons, 360 p.

Lerma, J.L., Akasheh, T., Haddad, N., and Cabrelles, M., 2011. Multispectral Sensors In Combination With Recording Tools For Cultural Heritage Documentation. Change Over Time, 1(2), pp. 236-250.

Lejeune, M., 1987. L'Art Mobilier Paléolithique et Mésolithique en Belgique. Artefacts 4. Editions du C.E.D.A., TreignesViroinval, Belgium.

Lompré, A., 2003. Une nouvelle étude techno-fonctionnelle appliquée à un ensemble magdalénien de bâtons percés. Préhistoire Anthropologie méditerranéennes, 12, pp. 147-163.

Marengo, E., Manfredi, M., Zerbinati, O., Robotti, E., Mazzucco, E., Gosetti, F., Bearman, G., et al., 2011. Development of a technique based on multi-spectral imaging for monitoring the conservation of cultural heritage objects. Analytica chimica acta, 706(2), pp. 229-237.

https://doi.org/10.1016/j.aca.2011.08.045.

Maté-González, M.Á., Yravedra, J., González-Aguilera, D., Palomeque-González, J.F., \& Domínguez-Rodrigo, M., 2015. Micro-photogrammetric characterization of cut marks on bones. Journal of Archaeological Science, 62, 128-142.

Maté-González, M.A., Aramendi, J., González-Aguilera, D., and Yravedra, J., 2017. Statistical Comparison between Low-Cost Methods for 3D Characterization of Cut-Marks on Bones. Remote sensing 9, 873, pp 1-17.

McCouat, P., 2014. Egyptian blue: the colour of technology. Journal of Art in Society.

http://www.artinsociety.com/egyptian-blue-the-colour-oftechnology.html (21/02/2019).

Neumüller, M., Reichinger, A., Rist, F., and Kern, C., 2014. 3D Printing for Cultural Heritage: Preservation, Accessibility, Research and Education. In: Ioannides, M., Quak, E., (eds) 3D Research Challenges in Cultural Heritage. Lecture Notes in Computer Science, vol 8355, pp. 119-134.

Ohta, J., 2017. Smart CMOS Image Sensors and Applications. CRC Press, $272 p$

Peltier, A., 1992. Fiche générale bâtons percés. In: H. BargeMahieu, H. Camps-Fabrer, V. Feruglio, A. Peltier, D. Ramseyer dir., Fiches typologiques de l'industrie osseuse préhistorique, cahier V : bâtons percés, baguettes, Treignes, CEDARC, pp. 734.

Remondino, F., \& Stylianidis, E. (2016). $3 D$ recording, documentation and management of cultural heritage (Vol. 2). Whittles Publishing.
Richards, A., 2005. Infrared spectral selection; it begins with the Detector. Photonics Handbook 2005. https://www.photonics.com/a25132/Infrared_Spectral_Selection _It_Begins_with_the (11/04/2018).

Rigaud, A., 2001. Les bâtons percés. Décors et fonctions possible. Gallia Préhistoire, 43, pp. 101-151.

Selden Jr., R.Z., Perttula, T.K., and O'Brien, M.J., 2014. Advances in Documentation, Digital Curation, Virtual Exhibition, and a Test of 3D Geometric Morphometrics: A Case Study of the Vanderpool Vessels from the Ancestral Caddo Territory. Advances in Archaeological Practice 2 (2), pp. 64-79.

Simon, C., Mansouri, A., Franck, M., and Boochs, F., 2013. Integration of $3 \mathrm{D}$ and multispectral data for cultural heritage applications: Survey and perspectives. Image and Vision Computing, 31 (1), pp.91-102.

Simpson Grant, M., 2000. The Use of ultraviolet induced visible fluorescence in the examination of museum objects, part II. Conserve O Gram 1/10.

Söderbergh, B., 1956. Les instruments de musique au Bas-Congo et dans les régions avoisinantes. The Ethnographical Museum of Sweden, Stockholm, pp. 214.

Twiesselmann, F., 1975. Description de trois gravures d'âge magdalénien provenant du Trou des Nutons et du Trou de Challeux (vallée de la Lesse, province de Namur) communication présentée le 27 janvier 1975. Bulletin de la Société Royale Belge d'Anthropologie et de Préhistoire, 86, pp. 151-161.

Verhoeven, G.J.J., 2017. The reflection of two fields Electromagnetic radiation and its role in (aerial) imaging. AAARGnews, number 55, pp. 13-18.

Webb, E.K., 2017. Reflected Infrared and 3D Imaging for Object Documentation. Journal of the American Institute for Conservation, 56:3-4, pp. 211-224.

https://doi.org/ 10.1080/01971360.2017.1359463

Zhao, S., Hou, M., Hu, Y., and Zhao, Q., 2018. Application of $3 \mathrm{D}$ model of cultural relics in virtual restoration. The International Archives of the Photogrammetry, Remote Sensing and Spatial Information Sciences, Volume XLII-3, pp. 24012405. 